\title{
The Fermentative Formation of CDP-Choline by Haploid Cells of Yeasts and the Change of the Temperature-sensitivity of a Mutant of a Yeast, Saccharomyces rouxi ${ }^{\dagger}$
}

\author{
Akira Kimura, Minotu Hashimoto and Haruhiko Mori* \\ Department of Food Science and Technology, Faculty of Agriculture, Kyoto University, \\ Kyoto 606, Japan \\ *Noda Institute for Scientific Research, Noda-Shi, Chiba, Japan
}

Received June 19, 1975

\begin{abstract}
Phosphorylation of CMP and formation of CDP-choline were tested with various haploid cells of yeasts. Most of them had more or less the ability, but a mutant (Lys-M7, alpha type) of Saccharomyces rouxii was found to lack the ability. Further study revealed the change of the temperature-sensitivity of the mutant, which could not produce CDP-choline when treated at $37^{\circ} \mathrm{C}$, whereas it could at $16^{\circ} \mathrm{C}$. The growth of the mutant was more sensitive to temperatures than that of the wild strain. The former did not grow at $36.3^{\circ} \mathrm{C}$, while the latter grew.
\end{abstract}

CMP was phosphorylated to CTP by the energy (ATP) generated through glycolysis $(J$. Bacteriol.; accepted 1976, Feb.) and converted to CDP-choline by not only dried cells of yeasts, ${ }^{1 \sim 3)}$ but also by intact cells treated with Triton X-100." The reaction mechanism was intensively investigated ${ }^{5,6}$, In addition to CDP-choline, other CDP-derivatives of choline analogues (aminoethanols) were formed in the same way. ${ }^{\text {" }}$

So far, most experiments were carried out by diploid cells of yeasts and some regulation mechanisms of CDP-choline formation were shown. ${ }^{3,5,6}$. This paper is concerned with the formation of CDP-choline by haploid cells of yeasts and with the finding of the change of a temperature-sensitivity in a mutant of Saccharomyces rouxii, which could not produce $\mathrm{CDP}$-choline when treated at $37^{\circ} \mathrm{C}$, but could do so at $16^{\circ} \mathrm{C}$.

\section{MATERIALS AND METHODS}

1) Microorganism. Various haploid cells of Saccharomyces cerevisiae and Saccharomyces rouxii

$\dagger$ No. IX in this series about "The Fermentative Formation of CDP-Choline." See references 2) and 6).

* Abbreviations used: CMP, cytidine 5'-monophosphate; CDP, cytidine 5'-diphosphate; CTP, cytidine 5'-triphosphate; EMS, ethyl methane sulfonate. were subjected to screening test to find strains, which could not form CDP-choline. These two species were adopted because $S$. cerevisiae has been genetically, widely investigated, and $S$. rouxii was a good producer of CDP-choline as shown in previous reports. ${ }^{1,2}$ Most of the haploid cells used in this experiment were kindly supplied from authors as listed in Table I, in which their genetic characters are listed together. Each strain was cultured at $28^{\circ} \mathrm{C}$ in the medium shown below. After harvest at the end of the growing phase, cells had been dried by an electric fan at room temperature for optional hours $(24 \sim 48 \mathrm{hr})$ until the temperature-sensitivity was noticed, and further dried over $\mathrm{P}_{2} \mathrm{O}_{5}$ in a desiccator for $24 \mathrm{hr}$. In order to check the change of the sensitivity to temperature, cells were dried under the controlled conditions $\left(16^{\circ} \mathrm{C}\right.$ and $37^{\circ} \mathrm{C}$ for $30 \mathrm{hr}$, respectively), and further dried over $\mathrm{P}_{2} \mathrm{O}_{5}$ as usual. A temperature gradient incubator (model $\mathrm{TN}-3$, Toyo Kagaku Sangyo Co., Ltd., Tokyo, Japan) was employed to test the effect of temperature on the growth of the mutant.

2) Media. Haploid cells were cultured in the nutrient medium containing $5 \%$ of glucose, $0.3 \%$ of peptone, $0.1 \%$ of yeast extract, $0.2 \%$ of $\mathrm{KH}_{2} \mathrm{PO}_{4}$, $0.3 \%$ of $\left(\mathrm{NH}_{4}\right)_{2} \mathrm{HPO}_{4}, 0.1 \%$ of $\mathrm{MgSO}_{4} \cdot 7 \mathrm{H}_{2} \mathrm{O}(\mathrm{pH} 6.5)$ and $2 \%$ of agar in the case of solid medium. For the isolation of auxotrophs, a modified minimal medium of Burkholder ${ }^{81}$ was used.

3) Isolation of mutants. A prototroph (S288C, alpha type) was cultured in $5 \mathrm{ml}$ of the above nutrient medium for $16 \mathrm{hr}$. After harvest, the cells were suspended in $8 \mathrm{ml}$ of $0.1 \mathrm{M}$ phosphate buffer (pH 7.0) containing $2 \%(\mathrm{v} / \mathrm{v})$ of ethyl methane sulfonate (EMS). Treatment with EMS at $30^{\circ} \mathrm{C}$ on shaking was stopped by mixing $0.1 \mathrm{ml}$ of the reaction mixture with $9.9 \mathrm{ml}$ 
Table I. Haploid Mutants of Saccharomyces Group Used

\begin{tabular}{|c|c|c|c|c|c|}
\hline $\begin{array}{l}\text { Haploid mutant } \\
\text { (Strain No.) }\end{array}$ & Species & $\begin{array}{l}\text { Mating } \\
\text { type }\end{array}$ & Genetic marker & Source & Reference \\
\hline (1) $\mathrm{mnn} l$ & S. cerevisiae & $a$ & $\operatorname{mnn} 1$ & \multicolumn{2}{|c|}{ C.E. Ballou et al. $(9,10,11)$} \\
\hline (2) $\mathrm{mnn} l$ & " & alpha & $\mathrm{mnn} I$ & $" r$ & " \\
\hline (3) $\mathrm{mnn} 2$ & " & $a$ & $\operatorname{mnn} 2$ & $"$ & $"$ \\
\hline (4) $\operatorname{mnn} 2$ & " & alpha & $\mathrm{mnn} 2$ & $" 1$ & $"$ \\
\hline (5) $\mathrm{S} 288 \mathrm{C}$ & S. cerevisiae & alpha & & H. Tamaki & \\
\hline (6) $\mathrm{C} 840-7 \mathrm{~B}$ & $"$ & $a$ & $\arg 4$ & $" \prime$ & \\
\hline (7) $\mathrm{C} 2634-3 \mathrm{~A}$ & $"$ & alpha & leu2, lys $2, \operatorname{try} 4$, tyr 1, met 3 & $"$ & \\
\hline (8) $708-7 \mathrm{~B}$ & S. species $^{a !}$ & alpha & $\arg 4$, STA1 & $" \prime$ & $(12)$ \\
\hline (9) S288C DG-M1 & S. cerevisiae & alpha & $\mathrm{mal}^{-}, \mathrm{gal}^{-}$, delayed growth & M. Hashimoto & \\
\hline (10) S288C Leu-M4 & " & $" \prime$ & $\mathrm{mal}^{-}, \mathrm{gal}^{-}, \mathrm{leu}^{-}$ & \& A. Kimura & \\
\hline (11) S288C Lys-M10 & " & " & $\mathrm{mal}^{-}, \mathrm{gal}^{-}, \mathrm{lys}^{-}$ & $" \prime$ & \\
\hline (12) S288C His-M13 & $"$ & " & 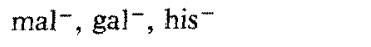 & $" r$ & \\
\hline (13) Arg-M1 & S. rouxii & $a$ & $\arg ^{-}$ & H. Mori & $(13,14)$ \\
\hline (14) Arg-M7 & $" 1$ & alpha & $\arg ^{-}$ & " & $"$ \\
\hline (15) Lys-M5 & " & $a$ & lys 2 & $" 1$ & $" 1$ \\
\hline (16) Lys-M7 & " & alpha & lys1 & $" \prime$ & $"$ \\
\hline (17) Lys-M12 & $" \prime$ & "r & lys 1 & $"$ & $"$ \\
\hline
\end{tabular}

a) A progeny of a hybrid between S. cerevisiae and S. diastaticus (IFO 1046).

of $3 \%$ of sodium thiosulfate solution, which destroyed or detoxicated EMS. The treated cells were spread on the nutrient medium, then mutants were isolated by replica method. The most mutants were obtained by $3 \sim 4$ hr treatment with EMS (killing rate was $99.9 \%$ ).

4) Reaction. Phosphorylation of CMP and formation of CDP-choline were achieved under usual conditions as described previously. ${ }^{1 \sim 4}$ ) The reaction mixture contained $800 \mathrm{~mm}$ of glucose, $200 \mathrm{~mm}$ of

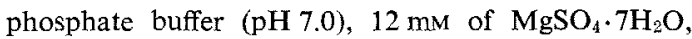
$20 \mathrm{~mm}$ of CMP, $100 \mathrm{~mm}$ of phosphorylcholine, and $100 \mathrm{mg}$ per $\mathrm{ml}$ of dried cells of a haploid strain. The total reaction mixture of $2.0 \mathrm{ml}$ was shaken at $28^{\circ} \mathrm{C}$ for indicated time (hr). The reaction was terminated by immersing the reaction tube in boiling water for $3 \mathrm{~min}$. After addition of $2.0 \mathrm{ml}$ of water, cells were removed by centrifugation at $3500 \times g$ for $5 \mathrm{~min}$ and the resulting supernatant was subjected to the analyses.

5) Analyses. The samples were applied onto Toyo filter paper No. 53, which was developed with a solvent system containing $95 \%$ ethanol $1 \mathrm{~m}$ ammonium acetate (2:1, by volume, $\mathrm{pH} 7.5$ ). Amounts of cytidine derivatives were determined by measuring their optical density at 260 and $290 \mathrm{~nm}$ after extracting their spots with $0.01 \mathrm{~N} \mathrm{HCl}$ from paper chromatograms.

\section{RESULTS AND DISCUSSION}

1) The formation of $C D P$-choline by mannan mutants of $S$. cerevisiae

First, we were interested in the mannan mutants, which were isolated and kindly supplied by Dr. Ballou. ${ }^{9 \sim 11)}$ As shown in Table I, mnn 1 (a) and mnnl (alpha) (strain Nos. 1 and 2 in Table I) lacked $\alpha-1,3$-mannosyltransferase, whereas $\operatorname{mnn} 2(a)$ and $\operatorname{mnn} 2$ (alpha) (strain Nos. 3 and 4) did $\alpha-1,2$-mannosyltransferase. Therefore, all of them had incomplete mannan layer of the cell wall. The dried cells of them could convert CMP to CDP-choline as shown in Fig. 1.

2) The formation of $C D P$-choline by various auxotrophic haploids of $S$. cerevisiae

Many haploid strains (strain Nos. $5 \sim 8$ in Table I) were kindly supplied by Dr. H. Tama$\mathrm{ki}$, who breeded $S$. diastaticus, ${ }^{12)}$ which could assimilate starch. Four mutants (strain Nos. $9 \sim 12$ ) were isolated by ourselves (M. H. and A. K.). As shown in Figs. 2 and 3, all of them produced some CDP-choline. However, the yields were rather low.

3) The formation of CDP-choline by auxotrophs of $S$. rouxii

$S$. rouxii is a haploid yeast, and one of the good producers of CDP-choline as shown in the previous papers. ${ }^{1,2}$ Therefore, it was of particular interest to test the mutants of $S$. 

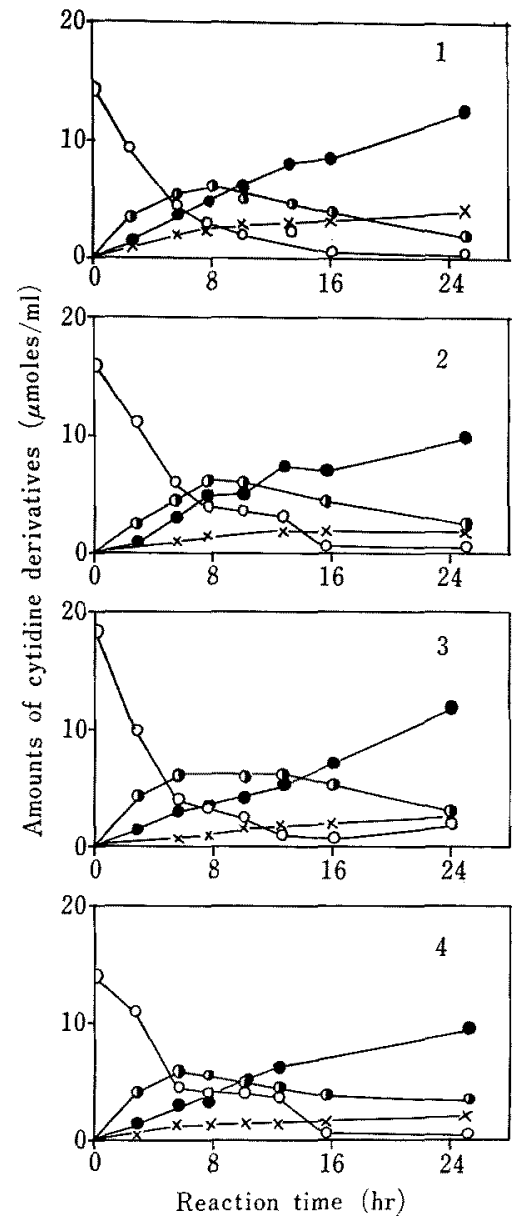

FIG. 1. Formation of CDP-Choline by Mannan Mutants of $S$. cerevisiae.

Figures show the results with mutants: mnnl (a) (Fig. 1-1), mnn1 (alpha) (Fig. 1-2), mnn2 (a) (Fig. 1-3), mnn2 (alpha) (Fig. 1-4), respectively. About these mutants see Table I (strain Nos. $1 \sim 4$ ). Ordinate shows amounts of cytidine derivatives ( $\mu$ moles per $\mathrm{ml}$ ) and abscissa does the reaction time (hr). The following symbols were used: CMP, (O); CDP + CTP, (O); CDP-choline, (๑); side products or mostly uracil, $(x)$. Numbers in figures correspond to the ones in Table I.

rouxii (strain Nos. $13 \sim 17$ ), which were obtained by one of the authors (H. M.). ${ }^{13,14}$ As shown in Fig. 4, some of them, especially Lys-M7 (strain No. 16), could not produce CDP-choline at all. Since the ability to convert CMP to CDP-choline had been thought to be rather stable, it was thought meaningful to investigate the mutant. As shown in the following chapter, further studies revealed that the temperature-sensitivity of the auxotroph
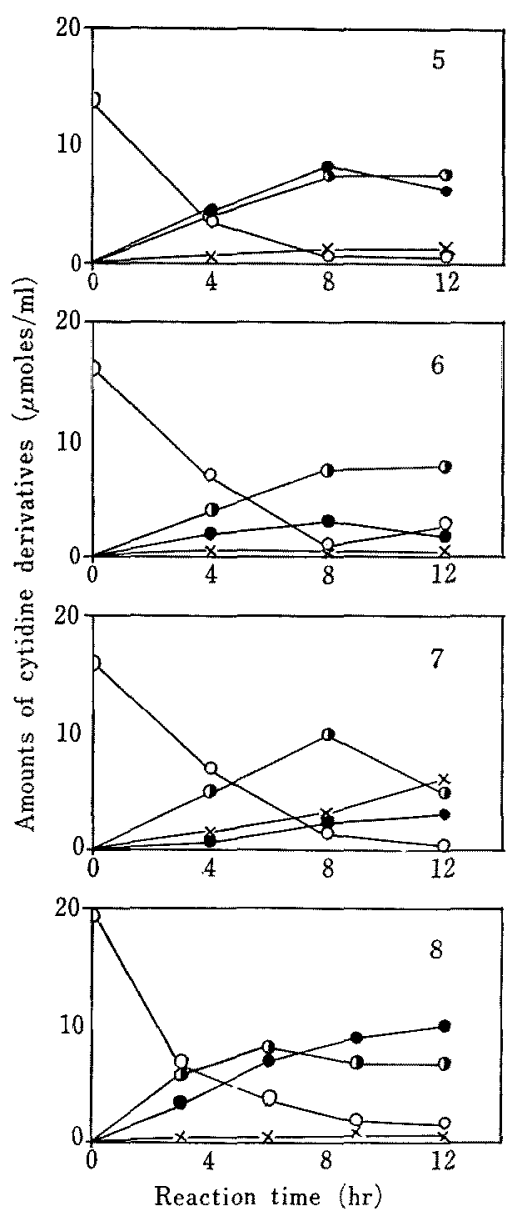

FIG. 2. Formation of CDP-Choline by Various Auxotrophs of $S$. cerevisiae.

Figures show the results with mutants: S288C (Fig, 2-5), C840-7B (Fig. 2-6), C2634-3A (Fig. 2-7), 7087B (Fig. 2-8), respectively. About these mutants see Table I (strain Nos. 5 8). CMP, (O); CDP CTP, (O) ; CDP-choline, (๑); side products or mostly uracil, $(\times)$. cf. Fig. 1 .

Lys-M7 of $S$. rouxii dramatically changed when compared with that of a wild strain (alpha).

4) The finding of a change of the temperaturesensitivity of the mutant of $S$. rouxii

The mutant Lys-M7 of $S$. rouxii was found to lack the ability to phosphorylate CMP and convert it to CDP-choline, while most other haploid mutants possessed the ability. Before getting into further experiments, we tried to reconfirm the previous results with this mutant, 

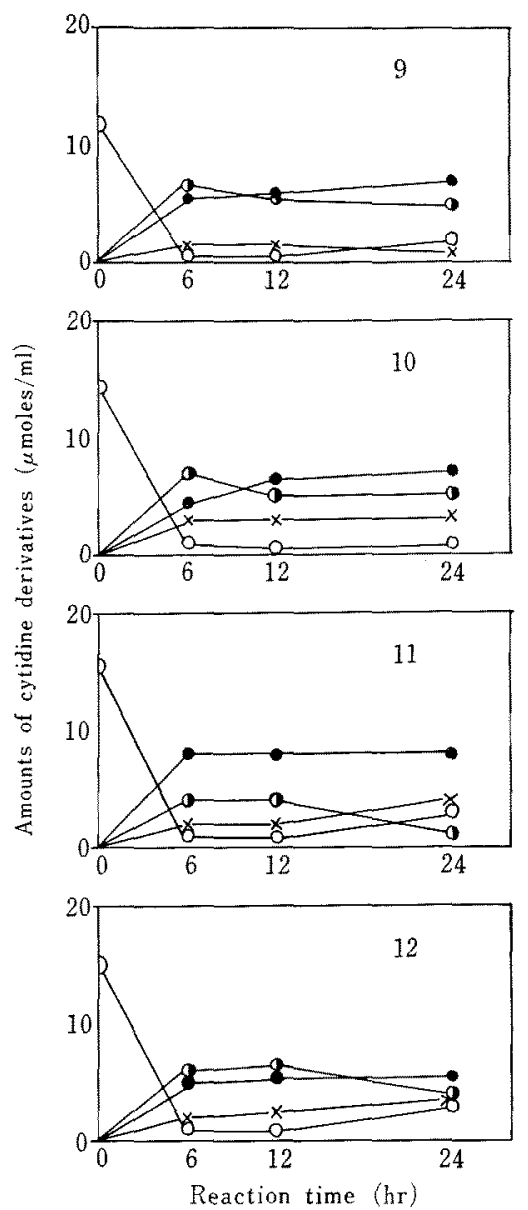

FIG. 3. Formation of CDP-Choline by Various Mutants of $S$ cerevisiae.

Figures show the results with mutants: S288C DGM1 (Fig. 3-9), S288C Leu-M4 (Fig. 3-10), S288C Lys-M10 (Fig. 3-11), S288C His-M13 (Fig. 3-12), respectively. About these mutants see Table I (strain Nos. 9 12). CMP, (O); CDP + CTP, (O); CDP-choline, $(1)$; side products or mostly uracil, $(\times)$. cf. Fig. 1.

and found that the result was not reproducible, while the results with other mutants were reproducible. In the first experiments as shown in Fig. 4, the mutant could not phosphorylate CMP, but in the second one it could phosphorylate CMP and converted it finally to CDP-choline. At first, this difference was not explainable, but later we awared that the previous experiments had been done in summer (1974), whereas the second ones in winter (1974 1975). The ability of phosphorylation of CMP and its conversion to CDP-choline by
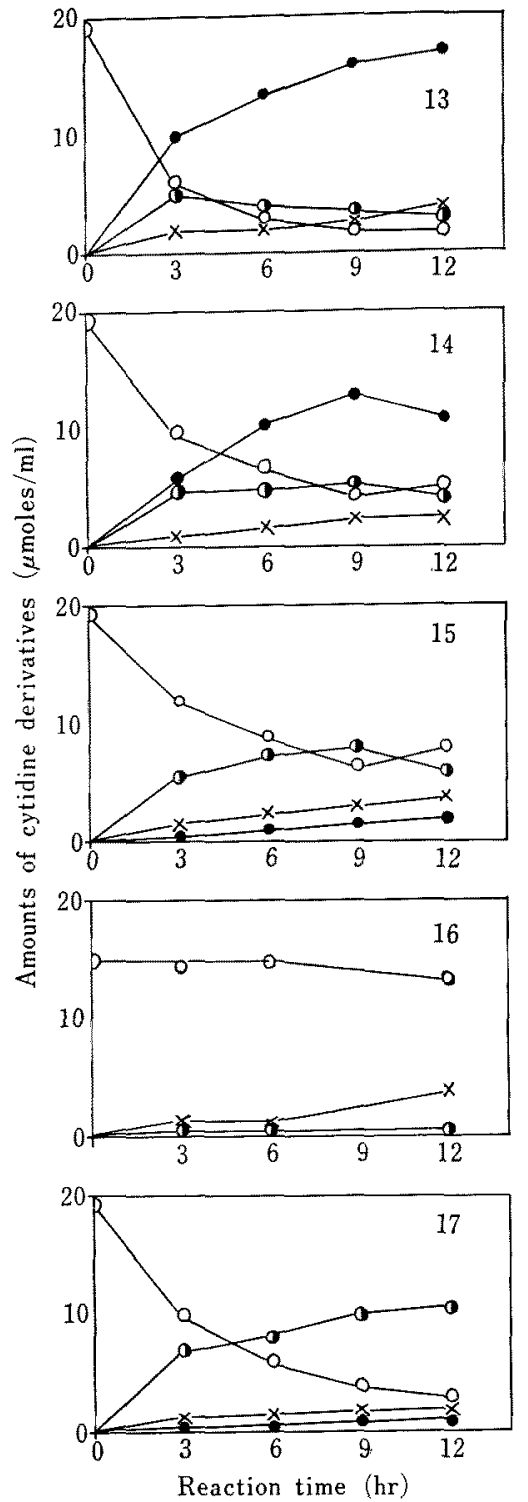

Fig. 4. Formation of CDP-Choline by Various Auxotrophs of $S$. rouxii.

Figures show the results with mutants: Arg-M1 (Fig. 4-13), Arg-M7 (Fig. 4-14), Lys-M5 (Fig. 4-15), Lys-M7 (Fig. 4-16), Lys-M12 (Fig. 4-17), respectively. About these mutants see Table I (strain Nos. 13 17). CMP, (O); CDP +CTP, (o); CDP-choline, (๑); side products or mostly uracil, $(\mathrm{x})$. cf. Fig. 1 .

this particular mutant seemed to depend very much upon the temperature, at which the cells were dried. Therefore, we set up the conditions of the different temperatures (16 and $37^{\circ} \mathrm{C}$ ), under which the cells were dried. Figure 5 shows the difference and influence of 

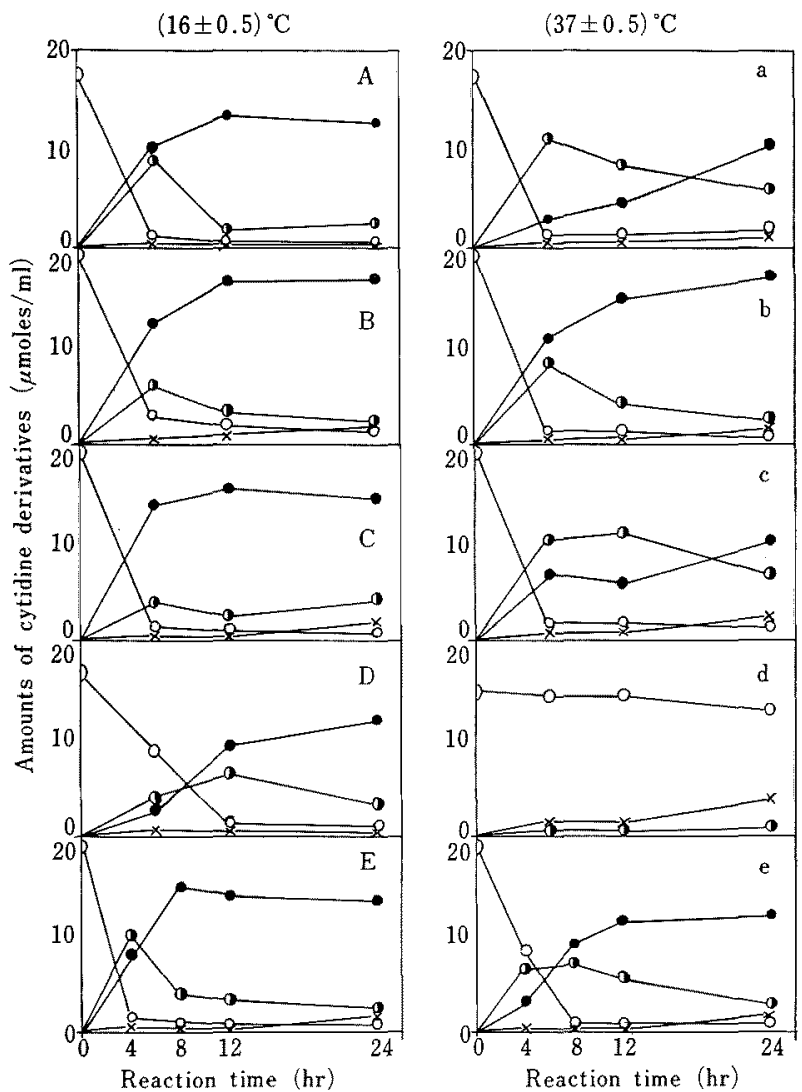

FIG. 5. Effect of Temperature on the Formation of CDP-Choline by Auxotrophs of S. rouxii.

Cells were divided into 2 fractions, each of which was treated at different temperatures (16 and $37^{\circ} \mathrm{C}$ ), respectively. Figures of the capital letters (A to $\mathrm{E}$, on the left) show the results obtained with cells dried at $16^{\circ} \mathrm{C}$, and figures of the small letters (a to e, on the right) show the results obtained with cells dried at $37^{\circ} \mathrm{C}$. Figures $A$ and a show the results with a prototroph NRRL 2547 (a), Figs. B and b with another prototroph NRRL 2548 (alpha), Figs. C and c with Lys-M5 (strain No. 15 in Table I), Figs. D and d with Lys-M7 (strain No. 16), Figs. E and e with Lys-M12 (strain No. 17), respectively.

the temperatures, at which cells were dried. Most strains of $S$. rouxii were somewhat sensitive to the temperature, and the mutant (Lys-M7, strain No. 16 in Table I) showed the remarkable response as shown in Figs. 5-D, and 5-d. When dried at around $16^{\circ} \mathrm{C}$, it preserved the ability to phosphorylate CMP and converted it to CDP-choline. On the other hand, when dried at $37^{\circ} \mathrm{C}$, it completely lost the ability. The reason why the amounts of CDP-choline were so small in the experiments with Lys-M5 and Lys-M12 (strain Nos. 15 and 17) in Fig. 4 might be that pyrophosphorylase was destroyed by the longer exposure for drying. Because, before we noticed the effect of the temperatures on the drying process, the process had been done under uncontrolled conditions, and yet we could find about $50 \%$ yield of CDP plus CTP in these cases. Comparing with CMP kinase system, pyrophosphorylase was rather labile.

If some enzymes were inactivated at the higher temperature, the growth of the mutant might be supposedly influenced at the higher temperature, too, or conversely this change of the temperature-sensitivity in drying might be a reflection of the temperature-sensitivity of this mutant. Therefore the effect of temperature on the growth of this mutant (Lys-M7) was checked by the use of a temperature 


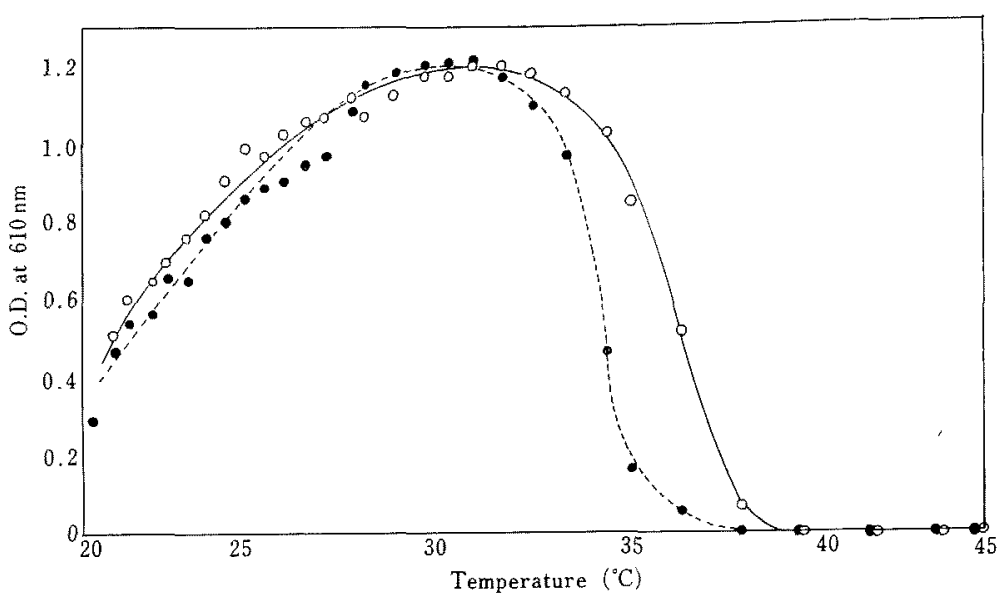

FIG. 6. Effect of Temperature on the Growth of a Prototroph and a Mutant of S, rouxii.

Cells were cultured on the temperature gradient incubator $(36 \mathrm{rpm})$. Cell gowth was measured with O.D. $610 \mathrm{~nm}$. A prototroph (NRRL-2548, alpha) (O) was cultured for $20 \mathrm{hr}$, while a auxotrophic mutant (Lys-M7, alpha, strain No. 16) (๑) was cultured for $32 \mathrm{hr}$. The temperature ranged from $20^{\circ} \mathrm{C}$ to $45^{\circ} \mathrm{C}$.

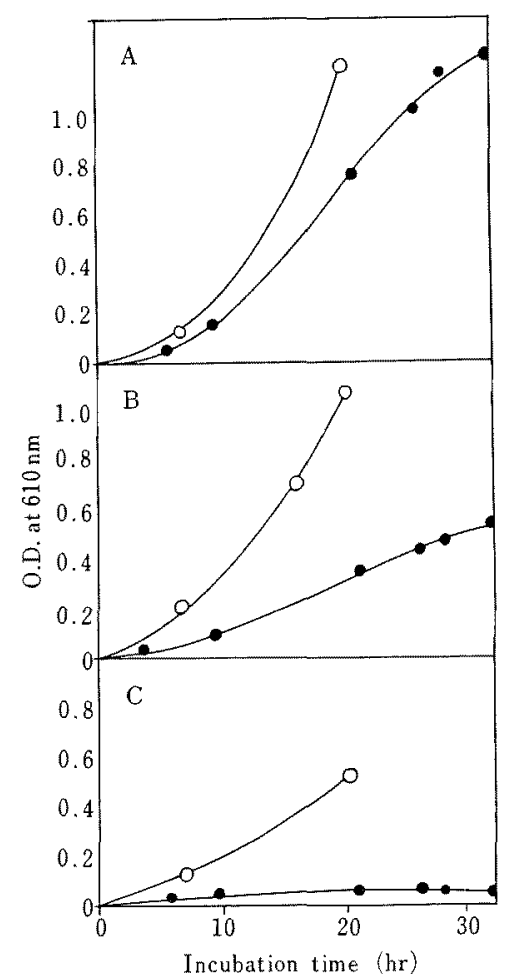

Fig. 7. Growth of a Prototroph and a Mutant of S. rouxii at Different Temperatures.

A prototroph (NRRL-2548, alpha) and a mutant (Lys-M7, alpha, strain No. 16) were grown at different temperatures: $31.8^{\circ} \mathrm{C}$ (Fig. 7-A), $34.3^{\circ} \mathrm{C}$ (Fig. 7-B), and $36.3^{\circ} \mathrm{C}$ (Fig. 7-C), respectively. The growth of the cells was measured at $610 \mathrm{~nm}$. gradient incubator and shown in Fig. 6 together with the growth of its prototroph. Figure 6 shows that at the higher temperature the growth of the mutant is inhibited stronger than that of the prototroph. The effect of temperature was expressed in another way as shown in Fig. 7. When incubated at $37^{\circ} \mathrm{C}$, both strains showed the poor growth. But that temperature $\left(37^{\circ} \mathrm{C}\right)$ was not fatal for them, for both of them grew when the temperature was changed to $28^{\circ} \mathrm{C}$. From these results, it was concluded that the mutant was more sensitive to the higher temperature than the prototroph, and that this sensitivity might relate the inactivation of phosphorylation of CMP. Further studies on the inactivation mechanism are now under way and will be published elsewhere.

Acknowledgement. The authors are deeply indebted to Dr. T. Tochikura for his kind encouragement and financial support throughout this work. They also want to express their sincere thanks to Dr. H.Tamaki of Doshisha Women's University for his kind support and useful advice. They are indebted to Drs. $H$. Kadota, and Y. Ishida of Department of Fishery, Kyoto University, for their kind support for lending us the valuable machines. They want to express their sincere thanks to Dr. Ballou for sending his valuable mutants. 


\section{REFERENCES}

1) T. Tochikura, A. Kimura, H. Kawai, T. Tachiki and T. Gotan, J. Ferment. Technol., 48, 763 (1970) ibid., 48, 769 (1970).

2) T. Tochikura, Y. Kariya and A. Kimura, ibid. 52, 637 (1974).

3) Y. Kariya, A. Kimura and T. Tochikura, ibid. 53, 278 (1975).

4) A. Kimura and M. Morita, Agr. Biol. Chem., 39, 1469 (1975).

5) A. Kimura and M. Morita and T. Tochikura, ibid., 35, 1955 (1971).

6) A. Kinura M. Morita and K. Murata, ibid., 39,
621 (1975).

7) Y. Kariya, K. Aisaka, A. Kimura and T. Tochikura, Amino Acid and Nucleic Acid, 29, 75 (1974).

8) R. R. Burkholder, Am. J. Botany, 30, 206 (1943).

9) C. Antalis, S. Fogel and C. E. Ballou, J. Biol. Chem., 248, 4655 (1973).

10) W. R. Raschke, K. A. Kern, C. Antalis and C. E. Ballou, ibid., 248, 4660 (1973).

11) C. E. Ballou, K. A. Kern and W. C. Raschke, ibid., 248, 4667 (1973).

12) H. Tamaki, SEIKEN ZIHO, report of the Kitara Institute for Biological Research, 20, 69 (1968).

13) H. Mori, J. Ferment. Technol., 50, 218 (1972).

14) H. Mori, ibid., 51, 379 (1973). 